\title{
A Coaxial Magnetic Gear With Halbach Permanent-Magnet Arrays
}

\author{
Linni Jian, Student Member, IEEE, and K. T. Chau, Senior Member, IEEE
}

\begin{abstract}
This paper proposes a coaxial magnetic gear that offers higher torque density, lower cogging torque, and lower iron losses than its counterparts. The key is to newly employ a Halbach permanent-magnet (PM) array to constitute the PM poles in the inner rotor and a partial Halbach array (two segments per pole) for the outer rotor. The corresponding magnetic field distributions, torque transmission, and torque ripples are analytically discussed. Then, the corresponding performances are quantitatively assessed by using the finite-element method.
\end{abstract}

Index Terms-Finite-element analysis, Halbach arrays, magnetic gear, torque transmission.

\section{INTRODUCTION}

$\mathbf{I}$ N ORDER TO transmit torque or force between separate parts moving at different speeds, mechanical gearboxes are extensively used, especially for wind power generation [1] and vehicular propulsion [2]. Because of their contact mechanisms, the associated transmission loss, gear noise and regular lubrication are inevitable.

The concept of noncontact magnetic gear coupling has been proposed for a decade [3]. It can transform torque and change speed by the interactive magnetic field between the permanentmagnet (PM) pieces mounted on two separate shafts, hence offering some distinct advantages, namely, minimum acoustic noise, free from maintenance, improved reliability, inherent overload protection, and physical isolation between input and output shafts. Despite these merits, the early magnetic gears in which parallel-axis topologies are mainly adopted have not gained much attention. The major drawback is the poor utilization of PMs, hence resulting in poor torque density and low transmission efficiency.

Recently, a high-performance magnetic gear has been proposed [4]-[6]. Because of the adoption of coaxial topology, the utilization of the PMs is improved significantly. Thus, it can provide higher torque density than the magnetic coupling. To strengthen the mechanical structure, a high-speed rotor with spoke type PMs is employed for a magnetic gear [7]. Also, various types of magnetic gears, such as the axial magnetic gear [8] and the linear magnetic gear [9], [10] are developed. Very recently, the coaxial magnetic gear has been directly

Manuscript received April 23, 2008; revised August 14, 2008; accepted August 20,2008. Date of current version May 21,2010. This work was supported by a grant (Project No. HKU7105/07E) from the Research Grants Council, Hong Kong Special Administrative Region, China. Paper no. TEC-00164-2008.

The authors are with the Electrical and Electronic Engineering Department, The University of Hong Kong, Pokfulam, Hong Kong (e-mail: lnjian@eee.hku.hk; ktchau@eee.hku.hk).

Digital Object Identifier 10.1109/TEC.2010.2046997

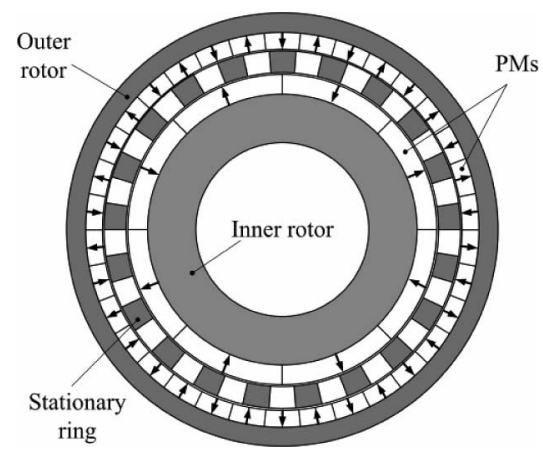

Fig. 1. Conventional coaxial magnetic gear.

mounted with electric machinery to achieve an integrated electric drive [11], [12]. However, this coaxial magnetic gear still suffers from the drawback of high torque ripples. Also, since its operating principle is not as intuitionistic as the parallel one, the available numerical analyses are insufficient to illustrate its physical insight.

It is well known that Halbach PM arrays hold some attractive features, namely, near-sinusoidal airgap flux density distribution, strong field intensity, and good self-shielding magnetization [13]-[16]. The purpose of this paper is to newly incorporate the attractive features of Halbach PM arrays into the coaxial magnetic gear. Thus, the resulting torque density becomes comparable with that of the mechanical gear, while the corresponding torque ripples and iron losses can be significantly reduced. Increasingly, with the use of analytical derivations, the physical insight of the proposed magnetic gear is brought forward. Hence, those "good" harmonics that contribute to torque transmission and those "bad" harmonics that are the cause of torque ripples can be analytically identified.

Section II will be devoted to describe the proposed configuration. Then, the proposed magnetic gear will be analytically discussed in Section III. In Section IV, the corresponding performances will be quantitatively assessed by using the finite-element method (FEM). Finally, conclusion is drawn in Section V.

\section{PRoposed Configuration}

Fig. 1 shows the topology of the conventional coaxial magnetic gear. It employs high-energy rare-earth PMs on both the inner rotor and the outer rotor, and has stationary ring sandwiched between the two rotors. The stationary ring takes charge of modulating the magnetic fields in two airgaps beside it. In order to form good magnetic paths as well as to reduce eddy current loss, the stationary ring is built of thin sheets of laminated 


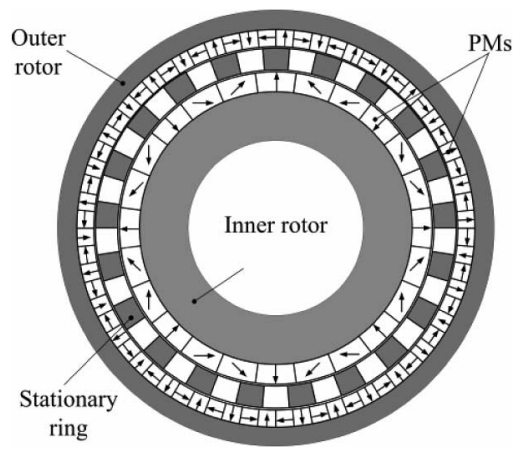

Fig. 2. Proposed coaxial magnetic gear.

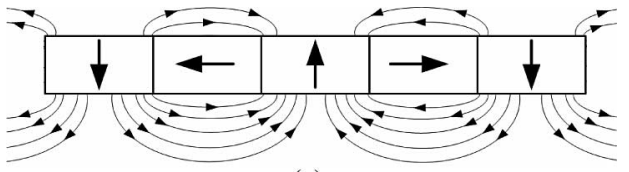

(a)

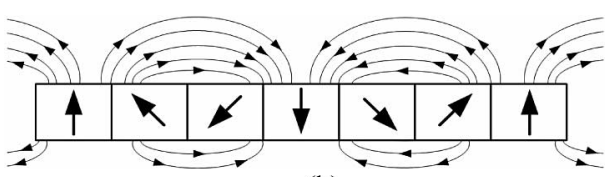

(b)

Fig. 3. Halbach PM arrays. (a) Two segments per pole. (b) Three segments per pole.

ferromagnetic materials. Also, epoxy is filled in its slots to enforce the structural strength for high torque transmission. Fig. 2 shows the proposed coaxial magnetic gear with the Halbach PM arrays. It has a similar structure with the magnetic gear given in Fig. 1, but with different orientations of PM pieces. The numbers of pole pairs on the inner and outer rotors are 4 and 17 , respectively. The number of ferromagnetic segments on the stationary ring is 21 .

Halbach PM arrays can generally be realized by discrete PM segments. By arranging PM segments with different magnetization directions properly, due to the superposition effect, the magnetic flux on one side of the device can be augmented while that on the other side is suppressed. Moreover, the field distribution becomes more sinusoidal because of the artfully designed magnetization directions for each PM segment. Fig. 3 shows the constructions of Halbach PM arrays with the numbers of PM segments per pole equal to 2 and 3 , respectively.

The choice of the number of segments per pole (NSP) is based on three considerations. First, the higher the value of NSP, the more sinusoidal the airgap flux densities can be resulted, which can help suppress the cogging torques. Second, a high value of NSP suffers from an increase of fabrication cost. Such increase of cost is particularly significant for the outer rotor that has a large number of poles. Third, different NSP values cause different magnetic field strengths, depending on the design of Halbach cylinders such as the radius and thickness [17]. The magnetic field strength of the main harmonic component actually governs the pull-out torque of the magnetic gear. When taking into account these considerations holistically, a tradeoff has to be made. Therefore, in the proposed magnetic gear, the

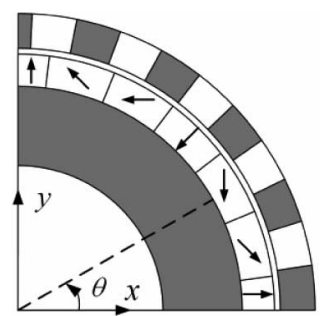

(a)

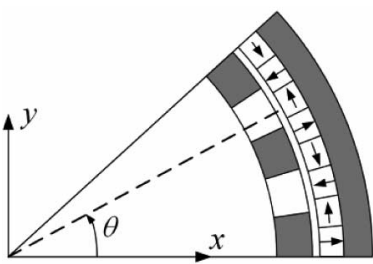

(b)

Fig. 4. Arrangements of PM segments. (a) One pole pair on inner rotor. (b) Two pole pairs on outer rotor.

numbers of PM segments per pole on the inner rotor and the outer rotor are chosen as 3 and 2, respectively.

Fig. 4 shows the arrangements of PM segments on the inner rotor and the outer rotor. The magnetization direction in each $\mathrm{PM}$ segment is given by

$$
\bar{M}=M_{x}+j M_{y}=M \cos ((1 \pm p) \theta)+j M \sin ((1 \pm p) \theta)
$$

where the minus case is for the inner rotor, the positive case is for the outer rotor, $p$ is the number of pole pairs, $\theta$ is the angle between the $x$-axis and the center line of each PM segment, $M=$ $B_{r} / \mu_{0}$ is the amplitude of remanent intrinsic magnetization, and $B_{r}$ is the remanence of the PM.

\section{THEORETICAL ANALYSIS}

The torque transmission between the two separated rotors relies on the interaction of the magnetic fields. Starting from the analysis of magnetic fields in the two airgaps, this section will deduce how the proposed device functions as a mechanical gear: transmitting stable torques when the rotors rotating at different speeds. The torque ripples will also be discussed.

\section{A. Magnetic Fields in Airgaps}

The magnetic fields in the coaxial magnetic gear are built up by the inner rotor PMs and the outer rotor PMs simultaneously. In order to analytically investigate the contribution of these magnetic fields to the torque, magnetic saturation of the stationary steel teeth is neglected, namely, the assumption of linear magnetic path [18] is adopted in such a way that the torque can be computed by using superposition. It should be noted that this assumption will not affect the constitution of magnetic field harmonics, and how they interact to achieve stable torque transmission when the two rotors rotating at different speeds.

First, the stationary ring is removed (see Fig. 5). Assuming that the PM is oriented according to ideal Halbach magnetization and the yokes are infinitely permeable, the field distribution in the air space can be modeled by the Laplacian and 


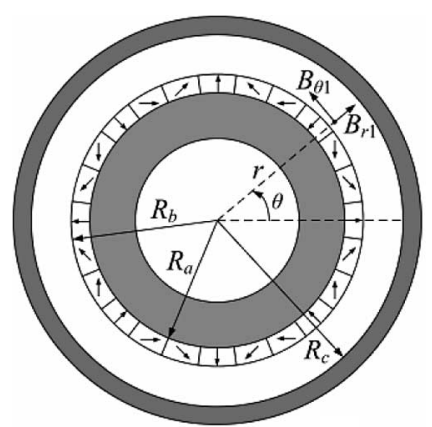

(a)

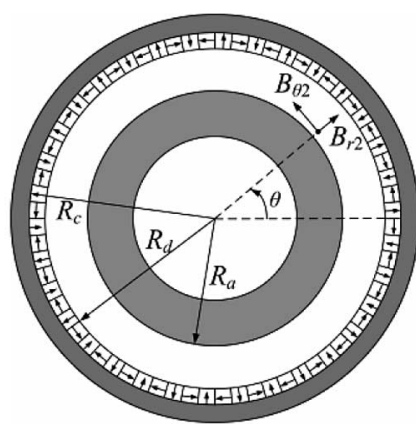

(b)

Fig. 5. Magnetic fields excited by rotors without stationary ring. (a) Inner rotor. (b) Outer rotor.

quasi-Poissonian equations of the scalar magnetic potential [19]. The radial and the tangential components of the magnetic flux density at a radial distance $r$ solely produced by the inner rotor and the outer rotor are given by

$$
\begin{aligned}
& B_{r 1}(r)=\frac{B_{r} p_{1}}{1+p_{1}} \frac{1-\left(R_{a} / R_{b}\right)^{p_{1}+1}}{1-\left(R_{a} / R_{c}\right)^{2 p_{1}}} \\
& \times\left[\left(\frac{r}{R_{c}}\right)^{p_{1}-1}\left(\frac{R_{b}}{R_{c}}\right)^{p_{1}+1}+\left(\frac{R_{b}}{r}\right)^{p_{1}+1}\right] \\
& \times \cos \left(p_{1}\left(\theta-\omega_{1} t\right)+p_{1} \theta_{10}\right) \\
& =A(r) \cos \left(p_{1}\left(\theta-\omega_{1} t\right)+p_{1} \theta_{10}\right) \\
& B_{\theta 1}(r)=\frac{-B_{r} p_{1}}{1+p_{1}} \frac{1-\left(R_{a} / R_{b}\right)^{p_{1}+1}}{1-\left(R_{a} / R_{c}\right)^{2 p_{1}}} \\
& \times\left[\left(\frac{r}{R_{c}}\right)^{p_{1}-1}\left(\frac{R_{b}}{R_{c}}\right)^{p_{1}+1}-\left(\frac{R_{b}}{r}\right)^{p_{1}+1}\right] \\
& \times \sin \left(p_{1}\left(\theta-\omega_{1} t\right)+p_{1} \theta_{10}\right) \\
& =B(r) \sin \left(p_{1}\left(\theta-\omega_{1} t\right)+p_{1} \theta_{10}\right) \\
& B_{r 2}(r)=\frac{-B_{r} p_{2}}{1-p_{2}} \frac{1-\left(R_{d} / R_{c}\right)^{p_{2}-1}}{1-\left(R_{a} / R_{c}\right)^{2 p_{2}}} \\
& \times\left[\left(\frac{r}{R_{d}}\right)^{p_{2}-1}+\left(\frac{r}{R_{d}}\right)^{p_{2}-1}\left(\frac{R_{a}}{r}\right)^{2 p_{2}}\right] \\
& \times \cos \left(p_{2}\left(\theta-\omega_{2} t\right)+p_{2} \theta_{20}\right) \\
& =C(r) \cos \left(p_{2}\left(\theta-\omega_{2} t\right)+p_{2} \theta_{20}\right) \\
& B_{\theta 2}(r)=\frac{B_{r} p_{2}}{1-p_{2}} \frac{1-\left(R_{d} / R_{c}\right)^{p_{2}-1}}{1-\left(R_{a} / R_{c}\right)^{2 p_{2}}} \\
& \times\left[\left(\frac{r}{R_{d}}\right)^{p_{2}-1}-\left(\frac{r}{R_{d}}\right)^{p_{2}-1}\left(\frac{R_{a}}{r}\right)^{2 p_{2}}\right] \\
& \times \sin \left(p_{2}\left(\theta-\omega_{2} t\right)+p_{2} \theta_{20}\right) \\
& =D(r) \sin \left(p_{2}\left(\theta-\omega_{2} t\right)+p_{2} \theta_{20}\right)
\end{aligned}
$$

where $p_{1}, p_{2}$ are the number of pole pairs on the inner and outer rotors, respectively, $R_{a}$ and $R_{b}$ are the inside and outside radii of the inner rotor, respectively, $R_{d}$ and $R_{c}$ are the inside and outside radii of the outer rotor, respectively, $\omega_{1}$ and $\omega_{2}$ are the rotational speeds of the inner and outer rotors, respectively, and

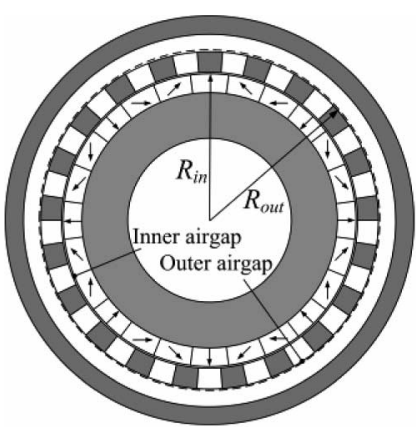

(a)

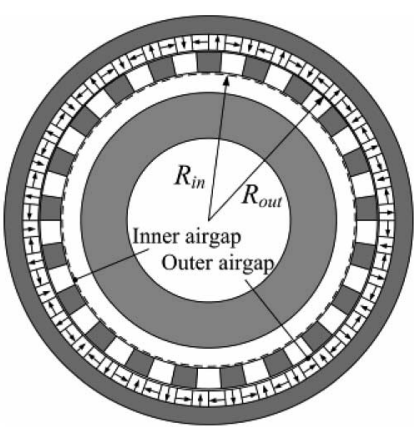

(b)
Fig. 6. Magnetic fields excited by rotors with stationary ring. (a) Inner rotor. (b) Outer rotor.

$\theta_{10}$ and $\theta_{20}$ are their initial phase angles. The coefficients $A, B$, $C$, and $D$ are all functions of radial distance $r$ and independent of the position angle $\theta$.

Second, the stationary ring is taken into account (see Fig. 6). Since magnetic saturation of the stationary ring is ignored, the ferromagnetic segments can be considered to have infinite permeability and hence be equipotential on both airgaps. Therefore, their distortion effect on the magnetic field is similar to the slotting effect in PM motors [20], which can be approximated by multiplying the original field distribution (without ferromagnetic segments) with a modulating function. Also, since this distortion occurs in two dimensions, the use of 2-D complex permeance function [21] is preferred. It should be noted that this approximation technique functions to analytically identify the constitution of the average torque for transmission and torque ripples, rather than to provide precise calculation.

Thus, the analytical expression of magnetic flux density with the stationary ring is given by

$$
B_{M}=B_{o} \lambda^{*}
$$

where $B_{M}$ and $B_{o}$ are the flux densities in the air space with and without the stationary ring, respectively, and $\lambda^{*}$ is the complex relative airgap permeance. In polar coordinates, it can further be written as

$$
\lambda^{*}=\lambda_{a} \vec{e}_{r}-\lambda_{b} \vec{e}_{\theta}
$$

For the inner and outer airgaps, it yields

$$
\begin{aligned}
\lambda_{a \_ \text {in }} & =\lambda_{0 \_ \text {in }}+\sum_{k=1}^{\infty} \lambda_{a k \_ \text {in }} \cos \left(k N_{s} \theta\right) \\
\lambda_{b \_ \text {in }} & =\sum_{k=1}^{\infty} \lambda_{b k \_ \text {in }} \sin \left(k N_{s} \theta\right) \\
\lambda_{a \_ \text {out }} & =\lambda_{0 \_ \text {out }}+\sum_{k=1}^{\infty} \lambda_{a k \_ \text {out }} \cos \left(k N_{s} \theta\right) \\
\lambda_{b \_ \text {out }} & =\sum_{k=1}^{\infty} \lambda_{b k \_ \text {out }} \sin \left(k N_{s} \theta\right)
\end{aligned}
$$

where $N_{s}$ is the number of ferromagnetic segments on the stationary ring, and $\lambda_{0 \_ \text {in }}, \lambda_{0 \_ \text {out }}, \lambda_{a k_{\text {_in }}}, \lambda_{a k_{-} \text {out }}, \lambda_{b k \_ \text {in }}$, and 
$\lambda_{b k_{-} \text {out }}$ are Fourier coefficients. Thus, the modulated flux density in the inner airgap excited by the inner rotor can be expressed as

$$
\begin{aligned}
B_{r 1 \_ \text {in }}= & \lambda_{a \_ \text {in }} B_{r 1}\left(R_{\mathrm{in}}\right)+\lambda_{b \_ \text {in }} B_{\theta 1}\left(R_{\mathrm{in}}\right) \\
= & \lambda_{0 \_ \text {in }} A\left(R_{\mathrm{in}}\right) \cos \left(p_{1}\left(\theta-\omega_{1} t\right)+p_{1} \theta_{10}\right) \\
& +\sum_{j= \pm 1} \sum_{k=1}^{\infty} \frac{\lambda_{a k \_ \text {in }} A\left(R_{\mathrm{in}}\right)-j \lambda_{b k \_ \text {in }} B\left(R_{\mathrm{in}}\right)}{2} \\
& \times \cos \left[\left(k N_{s}+j p_{1}\right)\left(\theta-\frac{j p_{1} \omega_{1} t}{k N_{s}+j p_{1}}\right)+j p_{1} \theta_{10}\right] \\
= & a_{0} \cos \left(p_{1}\left(\theta-\omega_{1} t\right)+p_{1} \theta_{10}\right) \\
& +\sum_{j= \pm 1} \sum_{k=1}^{\infty} a_{j k} \cos \left[p_{1 j k}\left(\theta-\omega_{1 j k} t\right)+j p_{1} \theta_{10}\right] \\
B_{\theta 1 \_ \text {in }}= & \lambda_{a \_ \text {in }} B_{\theta 1}\left(R_{\mathrm{in}}\right)-\lambda_{b \_ \text {in }} B_{r 1}\left(R_{\mathrm{in}}\right) \\
= & \lambda_{0 \_ \text {in }} B\left(R_{\mathrm{in}}\right) \sin \left(p_{1}\left(\theta-\omega_{1} t\right)+p_{1} \theta_{10}\right) \\
& -\sum_{j= \pm 1} \sum_{k=1}^{\infty} \frac{\lambda_{a k \_ \text {in }} B\left(R_{\mathrm{in}}\right)-j \lambda_{b k \_ \text {in }} A\left(R_{\mathrm{in}}\right)}{2} \\
& \times \sin \left[\left(k N_{s}+j p_{1}\right)\left(\theta-\frac{j p_{1} \omega_{1} t}{k N_{s}+j p_{1}}\right)+j p_{1} \theta_{10}\right] \\
= & b_{0} \sin \left(p_{1}\left(\theta-\omega_{1} t\right)+p_{1} \theta_{10}\right) \\
& +\sum_{j= \pm 1}^{\infty} \sum_{k=1}^{\infty} b_{j k} \sin \left[p_{1 j k}\left(\theta-\omega_{1 j k} t\right)+j p_{1} \theta_{10}\right] .
\end{aligned}
$$

Then, the flux density in the outer airgap excited by the inner rotor can be expressed as:

$$
\begin{aligned}
B_{r 1 \_ \text {out }}= & \lambda_{a_{-} \text {out }} B_{r 1}\left(R_{\text {out }}\right)+\lambda_{b_{-} \text {out }} B_{\theta 1}\left(R_{\text {out }}\right) \\
= & c_{0} \cos \left(p_{1}\left(\theta-\omega_{1} t\right)+p_{1} \theta_{10}\right) \\
& +\sum_{j= \pm 1} \sum_{k=1}^{\infty} c_{j k} \cos \left[p_{1 j k}\left(\theta-\omega_{1 j k} t\right)+j p_{1} \theta_{10}\right] \\
B_{\theta 1 \_ \text {out }}= & \lambda_{a \_ \text {out }} B_{\theta 1}\left(R_{\text {out }}\right)-\lambda_{b_{-} \text {out }} B_{r 1}\left(R_{\text {out }}\right) \\
= & d_{0} \sin \left(p_{1}\left(\theta-\omega_{1} t\right)+p_{1} \theta_{10}\right) \\
& +\sum_{j= \pm 1} \sum_{k=1}^{\infty} d_{j k} \sin \left[p_{1 j k}\left(\theta-\omega_{1 j k} t\right)+j p_{1} \theta_{10}\right] .
\end{aligned}
$$

Similarly, the corresponding flux densities excited by the outer rotor can be expressed as

$$
\begin{aligned}
B_{r 2 \_ \text {in }}= & \lambda_{a \_ \text {in }} B_{r 2}\left(R_{\text {in }}\right)+\lambda_{b \_ \text {in }} B_{\theta 2}\left(R_{\text {in }}\right) \\
= & e_{0} \cos \left(p_{2}\left(\theta-\omega_{2} t\right)+p_{2} \theta_{20}\right) \\
& +\sum_{j= \pm 1} \sum_{k=1}^{\infty} e_{j k} \cos \left[p_{2 j k}\left(\theta-\omega_{2 j k} t\right)+j p_{2} \theta_{20}\right]
\end{aligned}
$$

$$
\begin{aligned}
B_{\theta 2 \_ \text {in }}= & \lambda_{a \_ \text {in }} B_{\theta 2}\left(R_{\text {in }}\right)-\lambda_{b \_ \text {in }} B_{r 2}\left(R_{\text {in }}\right) \\
= & f_{0} \sin \left(p_{2}\left(\theta-\omega_{2} t\right)+p_{2} \theta_{20}\right) \\
& +\sum_{j= \pm 1} \sum_{k=1}^{\infty} b_{j k} \sin \left[p_{2 j k}\left(\theta-\omega_{2 j k} t\right)+j p_{2} \theta_{20}\right] \\
B_{r 2 \_ \text {out }}= & \lambda_{a \_ \text {out }} B_{r 2}\left(R_{\text {out }}\right)+\lambda_{b_{\text {_out }}} B_{\theta 2}\left(R_{\text {out }}\right) \\
= & g_{0} \cos \left(p_{2}\left(\theta-\omega_{2} t\right)+p_{2} \theta_{20}\right) \\
& +\sum_{j= \pm 1} \sum_{k=1}^{\infty} g_{j k} \cos \left[p_{2 j k}\left(\theta-\omega_{2 j k} t\right)+j p_{2} \theta_{20}\right] \\
B_{\theta 2 \_ \text {out }}= & \lambda_{a \_ \text {out }} B_{\theta 2}\left(R_{\text {out }}\right)-\lambda_{b_{-} \text {out }} B_{r 2}\left(R_{\text {out }}\right) \\
= & h_{0} \sin \left(p_{2}\left(\theta-\omega_{2} t\right)+p_{2} \theta_{20}\right) \\
& +\sum_{j= \pm 1} \sum_{k=1}^{\infty} h_{j k} \sin \left[p_{2 j k}\left(\theta-\omega_{2 j k} t\right)+j p_{2} \theta_{20}\right]
\end{aligned}
$$

where $R_{\text {in }}$ and $R_{\text {out }}$ are the radii of the inner and outer airgaps respectively. The coefficients $a_{j k}, b_{j k}, c_{j k}, d_{j k}, e_{j k}, f_{j k}, g_{j k}$, and $h_{j k}$ are all constants. The pole-pair number of the harmonic components is given by

$$
\begin{aligned}
p_{i j k}=k N_{s}+j p_{i}, \quad i=1,2, \quad j & =1,-1, \\
& k=1,2, \ldots, \infty .
\end{aligned}
$$

Therefore, the corresponding rotational speed is given by

$$
\omega_{i j k}=\frac{j p_{i} \omega_{i}}{k N_{s}+j p_{i}} .
$$

Finally, ignoring the nonlinear factors of the magnetic path, the resultant magnetic fields in the airgaps are obtained as

$$
\begin{aligned}
B_{r_{-} \text {in }}= & B_{r 1 \_ \text {in }}+B_{r 2 \_ \text {in }} \\
= & a_{0} \cos \left(p_{1}\left(\theta-\omega_{1} t\right)+p_{1} \theta_{10}\right) \\
& +e_{0} \cos \left(p_{2}\left(\theta-\omega_{2} t\right)+p_{2} \theta_{20}\right) \\
& +\sum_{j= \pm 1} \sum_{k=1}^{\infty}\left[\begin{array}{c}
a_{j k} \cos \left(p_{1 j k}\left(\theta-\omega_{1 j k} t\right)+j p_{1} \theta_{10}\right) \\
+e_{j k} \cos \left(p_{2 j k}\left(\theta-\omega_{2 j k} t\right)+j p_{2} \theta_{20}\right)
\end{array}\right]
\end{aligned}
$$

$$
\begin{aligned}
B_{\theta \_ \text {in }}= & B_{\theta 1 \_ \text {in }}+B_{\theta 2 \_ \text {in }} \\
= & b_{0} \sin \left(p_{1}\left(\theta-\omega_{1} t\right)+p_{1} \theta_{10}\right) \\
& +f_{0} \sin \left(p_{2}\left(\theta-\omega_{2} t\right)+p_{2} \theta_{20}\right) \\
& +\sum_{j= \pm 1} \sum_{k=1}^{\infty}\left[\begin{array}{c}
b_{j k} \sin \left(p_{1 j k}\left(\theta-\omega_{1 j k} t\right)+j p_{1} \theta_{10}\right) \\
+f_{j k} \sin \left(p_{2 j k}\left(\theta-\omega_{2 j k} t\right)+j p_{2} \theta_{20}\right)
\end{array}\right]
\end{aligned}
$$




$$
\begin{aligned}
B_{r_{\text {_out }}=} & B_{r_{1} \_ \text {out }}+B_{r 2_{\text {out }}} \\
= & c_{0} \cos \left(p_{1}\left(\theta-\omega_{1} t\right)+p_{1} \theta_{10}\right) \\
& +g_{0} \cos \left(p_{2}\left(\theta-\omega_{2} t\right)+p_{2} \theta_{20}\right) \\
& +\sum_{j= \pm 1} \sum_{k=1}^{\infty}\left[\begin{array}{c}
c_{j k} \cos \left(p_{1 j k}\left(\theta-\omega_{1 j k} t\right)+j p_{1} \theta_{10}\right) \\
+g_{j k} \cos \left(p_{2 j k}\left(\theta-\omega_{2 j k} t\right)+j p_{2} \theta_{20}\right)
\end{array}\right]
\end{aligned}
$$

$$
\begin{aligned}
B_{\theta \_ \text {out }}= & B_{\theta 1 \_ \text {out }}+B_{\theta 2 \_ \text {out }} \\
= & d_{0} \sin \left(p_{1}\left(\theta-\omega_{1} t\right)+p_{1} \theta_{10}\right) \\
& +h_{0} \sin \left(p_{2}\left(\theta-\omega_{2} t\right)+p_{2} \theta_{20}\right) \\
& +\sum_{j= \pm 1} \sum_{k=1}^{\infty}\left[\begin{array}{c}
d_{j k} \sin \left(p_{1 j k}\left(\theta-\omega_{1 j k} t\right)+j p_{1} \theta_{10}\right) \\
+h_{j k} \sin \left(p_{2 j k}\left(\theta-\omega_{2 j k} t\right)+j p_{2} \theta_{20}\right)
\end{array}\right] .
\end{aligned}
$$

\section{B. Torque Transmission}

In order to function as a mechanical gear, the proposed magnetic gear should achieve stable torque transmission while the rotors rotating at different speeds. By choosing proper combination of $\left(p_{1}, p_{2}, N_{s}\right)$, this goal can be reached. They are governed by

$$
N_{s}=p_{1}+p_{2}
$$

The corresponding inner and outer rotors are rotating at the speed of $\omega_{1}$ and $\omega_{2}$, respectively, which are governed by

$$
\omega_{2}=-\frac{p_{1}}{p_{2}} \omega_{1}=-G_{r} \omega_{1}
$$

where $G_{r}$ is called the gear ratio, and the minus notation indicates that the two rotors rotate in opposite directions.

The average magnetic torque developed on the inner rotor can be obtained by calculating the Maxwell stress in the inner airgap

$$
T_{m \_ \text {in }}=\frac{L_{\mathrm{ef}} R_{\mathrm{in}}^{2}}{\mu_{0}} \int_{0}^{2 \pi} B_{r_{\text {_in }}} B_{\theta \_ \text {in }} d \theta
$$

where $L_{\text {ef }}$ is the effective axial length.

From (22) and (23), it can be found that both the radial and tangential flux densities in the inner airgap are the sum of infinite harmonic terms. Each term can be generally expressed as

$$
\begin{aligned}
& b_{r_{\text {_in }}}=\delta \cos \left(p_{m} \theta+\alpha\right) \\
& b_{\theta \text { in }}=\varepsilon \sin \left(p_{n} \theta+\beta\right)
\end{aligned}
$$

where $p_{m}$ and $p_{n}$ are the pole-pair numbers, and $\alpha$ and $\beta$ are the phase angles. The coefficients $\delta$ and $\varepsilon$ are constants, which are independent of the position angle $\theta$. Thus, it yields

$$
\begin{aligned}
\int_{0}^{2 \pi} b_{r \_ \text {in }} b_{\theta \_ \text {in }} d \theta & =\int_{0}^{2 \pi} \delta \varepsilon \cos \left(p_{m} \theta+\alpha\right) \sin \left(p_{n} \theta+\beta\right) d \theta \\
& = \begin{cases}0, & p_{m} \neq p_{n} \\
\delta \varepsilon \pi \sin (\beta-\alpha), & p_{m}=p_{n} .\end{cases}
\end{aligned}
$$

It can be found that the product term $b_{r_{\perp} \text { in }} b_{\theta}$ in can contribute to the average magnetic torque if it satisfies the following two rules:

1) R1: $b_{r_{-} \text {in }}$ and $b_{\theta}{ }_{\text {in }}$ have the same pole-pair number;

2) R2: $b_{r \_ \text {in }}$ and $b_{\theta \_ \text {in }}$ have different phase angles.

Table I illustrates the overall combinations of $b_{r}$ in and $b_{\theta}$ _in, in which the first row lists all the pole-pair numbers of the radial flux density harmonics, and the first column lists that of the tangential flux density harmonics. The intersection of each row and column is marked with either 0 or 1 , where 1 signifies that the corresponding product term $b_{r_{-} \text {in }} b_{\theta}$ in may contribute to the average magnetic torque, whereas 0 means no contribution. These can be determined by considering (20), (21), (26), (27), and the rules R1 and R2. The harmonics with the pole-pair number marked with 1 are called effective harmonics. Consequently, Table II gives the pole-pair numbers of the effective harmonics in the inner airgap and their contributed magnetic torques.

The average magnetic torque developed on the outer rotor can be obtained by calculating the Maxwell stress in the outer airgap

$$
T_{m \_ \text {out }}=\frac{L_{\mathrm{ef}} R_{\text {out }}^{2}}{\mu_{0}} \int_{0}^{2 \pi} B_{r_{\text {_out }}} B_{\theta \_ \text {out }} d \theta .
$$

Consequently, the pole-pair numbers of the effective harmonics in the outer airgap and their contributed magnetic torques are shown in Table III. Both Tables II and III demonstrate that the magnetic torques are sinusoidal functions of the initial phase angle difference of the two rotors. Since they are independent of time, the proposed magnetic gear can transmit stable magnetic torque while realize speed variation as governed by (27).

\section{Torque Ripples}

As shown in Tables II and III, when the PMs are oriented according to ideal Halbach magnetization, the developed magnetic torques only depend on $\left(p_{2} \theta_{20}-p_{1} \theta_{10}\right)$, hence resulting no torque ripples. However, for Halbach PM array with discrete PM segments, torque ripples do exist.

For nonideal Halbach magnetization, the flux density at a radial distance $r$ solely produced by the inner rotor is no longer purely sinusoidal and should be written as

$$
\begin{aligned}
& B_{r 1}^{\prime}(r)=\sum_{m=1,3,5, \ldots} A_{m}(r) \cos \left(m p_{1}\left(\theta-\omega_{1} t\right)+m p_{1} \theta_{10}\right) \\
& B_{\theta 1}^{\prime}(r)=\sum_{m=1,3,5, \ldots} B_{m}(r) \sin \left(m p_{1}\left(\theta-\omega_{1} t\right)+m p_{1} \theta_{10}\right) .
\end{aligned}
$$

Taking into account the stationary ring, the modulated flux density in the inner airgap excited by the inner rotor can be expressed as

$$
\begin{aligned}
B_{r 1 \_ \text {in }}^{\prime}= & a_{0}^{\prime} \cos \left(p_{1}\left(\theta-\omega_{1} t\right)+p_{1} \theta_{10}\right) \\
& +\sum_{j= \pm 1} \sum_{m=1,3,5, \ldots} \sum_{k=1}^{\infty} a_{j k m} \\
& \times \cos \left[p_{1 j k m}\left(\theta-\omega_{1 j k m} t\right)+j m p_{1} \theta_{10}\right]
\end{aligned}
$$


TABLE I

COMBINATION OF FLUX DENSITY HARMONICS IN INNER AIRGAP

\begin{tabular}{|c|c|c|c|c|c|c|c|c|c|c|c|c|c|c|c|c|c|c|c|c|c|c|c|}
\hline \multirow{2}{*}{\multicolumn{2}{|c|}{$b_{\theta} b_{r i n}{ }^{i n}$}} & \multirow{2}{*}{$p_{1}$} & \multirow{2}{*}{$p_{2}$} & \multicolumn{5}{|c|}{$p_{11 k}$} & \multicolumn{5}{|c|}{$p_{1-1 k}$} & \multicolumn{5}{|c|}{$p_{21 k}$} & \multicolumn{5}{|c|}{$p_{2-1 k}$} \\
\hline & & & & $p_{111}$ & $p_{112}$ & $\ldots$ & $p_{11 n}$ & $\ldots$ & $\overrightarrow{p_{1-1}}$ & $p_{1-12}$ & $\ldots$ & $p_{1-1 n}$ & $\ldots$ & $p_{211}$ & $p_{212}$ & $\ldots$ & $p_{21 n}$ & $\cdots$ & $p_{2-11}$ & $p_{2-12}$ & $\ldots$ & $p_{2-1 n}$ & $\ldots$ \\
\hline \multicolumn{2}{|c|}{$p_{1}$} & 0 & 0 & 0 & 0 & $\ldots$ & 0 & $\ldots$ & 0 & 0 & $\ldots$ & 0 & $\ldots$ & 0 & 0 & $\ldots$ & 0 & $\ldots$ & 1 & 0 & $\ldots$ & 0 & $\ldots$ \\
\hline \multicolumn{2}{|c|}{$p_{2}$} & 0 & 0 & 0 & 0 & $\cdots$ & 0 & $\ldots$ & 1 & 0 & $\cdots$ & 0 & $\cdots$ & 0 & 0 & $\ldots$ & 0 & $\cdots$ & 0 & 0 & $\cdots$ & 0 & $\cdots$ \\
\hline \multirow{5}{*}{$p_{11 k}$} & $p_{111}$ & 0 & 0 & 0 & 0 & $\ldots$ & 0 & $\ldots$ & 0 & 0 & $\ldots$ & 0 & $\ldots$ & 0 & 0 & $\ldots$ & 0 & $\ldots$ & 0 & 1 & $\ldots$ & 0 & $\ldots$ \\
\hline & $p_{112}$ & 0 & 0 & 0 & 0 & $\ldots$ & 0 & $\ldots$ & 0 & 0 & $\ldots$ & 0 & $\ldots$ & 0 & 0 & $\ldots$ & 0 & $\ldots$ & 0 & 0 & $\because$ & 0 & $\cdots$ \\
\hline & $\vdots$ & $\vdots$ & $\vdots$ & $\vdots$ & $\vdots$ & $\because$ & 0 & $\ldots$ & $\vdots$ & $\vdots$ & $\because$ & 0 & $\ldots$ & $\vdots$ & $\vdots$ & $\because$ & 0 & $\ldots$ & $\vdots$ & $\vdots$ & $\because$ & 1 & $\ldots$ \\
\hline & $p_{11 n}$ & 0 & 0 & 0 & 0 & 0 & 0 & $\ldots$ & 0 & 0 & 0 & 0 & $\ldots$ & 0 & 0 & 0 & 0 & $\ldots$ & 0 & 0 & 0 & 0 & $\because$ \\
\hline & $\vdots$ & $\vdots$ & $\vdots$ & $\vdots$ & $\vdots$ & $\vdots$ & $\vdots$ & $\because$ & $\vdots$ & $\vdots$ & $\vdots$ & $\vdots$ & $\because$ & : & $\vdots$ & $\vdots$ & $\vdots$ & $\because$ & $\vdots$ & : & $\vdots$ & $\vdots$ & $\ddots$ \\
\hline \multirow{5}{*}{$p_{1-1 k}$} & $p_{1-11}$ & 0 & 1 & 0 & 0 & $\ldots$ & 0 & $\ldots$ & 0 & 0 & $\ldots$ & 0 & $\ldots$ & 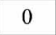 & 0 & $\ldots$ & 0 & $\cdots$ & 0 & 0 & $\ldots$ & 0 & $\ldots$ \\
\hline & $p_{1-12}$ & 0 & 0 & 0 & 0 & $\ldots$ & 0 & $\ldots$ & 0 & 0 & $\ldots$ & 0 & $\ldots$ & 1 & 0 & $\ldots$ & 0 & $\ldots$ & 0 & 0 & $\ldots$ & 0 & $\ldots$ \\
\hline & $\vdots$ & $\vdots$ & $\vdots$ & : & : & $\because$ & 0 & $\ldots$ & : & $\vdots$ & $\because$ & 0 & $\ldots$ & : & $\ddots$ & $\ddots$ & 0 & $\ldots$ & $\vdots$ & $\vdots$ & $\because$ & 0 & $\ldots$ \\
\hline & $p_{1-1 n}$ & 0 & 0 & 0 & 0 & 0 & 0 & $\ldots$ & 0 & 0 & 0 & 0 & $\ldots$ & 0 & 0 & 1 & 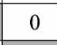 & $\ldots$ & 0 & 0 & 0 & 0 & $\ldots$ \\
\hline & $\vdots$ & $\vdots$ & 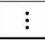 & $\vdots$ & $\vdots$ & $\vdots$ & $\vdots$ & $\because$ & $\vdots$ & $\vdots$ & $\vdots$ & $\vdots$ & $\because$ & $\vdots$ & $\vdots$ & $\vdots$ & $\because$ & $\because$ & $\vdots$ & $\vdots$ & $\vdots$ & $\vdots$ & $\because$ \\
\hline \multirow{5}{*}{$p_{21 k}$} & $p_{211}$ & 0 & 0 & 0 & 0 & $\cdots$ & 0 & $\ldots$ & 0 & 1 & $\cdots$ & 0 & $\ldots$ & 0 & 0 & $\ldots$ & 0 & $\ldots$ & 0 & 0 & $\ldots$ & 0 & $\ldots$ \\
\hline & $p_{212}$ & 0 & 0 & 0 & 0 & $\cdots$ & 0 & $\ldots$ & 0 & 0 & $\because$ & 0 & $\cdots$ & 0 & 0 & $\cdots$ & 0 & $\ldots$ & 0 & 0 & $\ldots$ & 0 & $\cdots$ \\
\hline & $\vdots$ & $\vdots$ & $\vdots$ & $\vdots$ & $\vdots$ & $\ddots$ & 0 & $\ldots$ & $\vdots$ & $\vdots$ & $\ddots$ & 1 & $\ldots$ & $\vdots$ & $\vdots$ & $\ddots$ & 0 & $\ldots$ & $\vdots$ & $\vdots$ & $\ddots$ & 0 & $\ldots$ \\
\hline & $p_{21 n}$ & 0 & 0 & 0 & 0 & 0 & 0 & $\ldots$ & 0 & 0 & 0 & 0 & $\because$ & 0 & 0 & 0 & 0 & $\ldots$ & 0 & 0 & 0 & 0 & $\ldots$ \\
\hline & $\vdots$ & $\vdots$ & $\vdots$ & $\vdots$ & $\vdots$ & $\vdots$ & $\vdots$ & $\because$ & $\vdots$ & $\vdots$ & $\vdots$ & $\vdots$ & $\because$ & $\vdots$ & $\vdots$ & $\vdots$ & $\vdots$ & $\because$ & $\vdots$ & $\vdots$ & $\vdots$ & $\vdots$ & $\because$ \\
\hline \multirow{5}{*}{$p_{2-1 k}$} & $p_{2-11}$ & 1 & 0 & 0 & 0 & $\ldots$ & 0 & $\ldots$ & 0 & 0 & $\ldots$ & 0 & $\cdots$ & 0 & 0 & $\ldots$ & 0 & $\cdots$ & 0 & 0 & $\ldots$ & 0 & $\ldots$ \\
\hline & $p_{2-12}$ & 0 & 0 & 1 & 0 & $\ldots$ & 0 & $\ldots$ & 0 & 0 & $\ldots$ & 0 & $\cdots$ & 0 & 0 & $\ldots$ & 0 & $\cdots$ & 0 & 0 & $\ldots$ & 0 & $\ldots$ \\
\hline & $\vdots$ & $\vdots$ & $\vdots$ & $\vdots$ & $\ddots$ & $\because$ & 0 & $\ldots$ & $\vdots$ & $\vdots$ & $\because$ & 0 & $\ldots$ & $\vdots$ & $\vdots$ & $\because$ & 0 & $\ldots$ & $\vdots$ & $\vdots$ & $\because$ & 0 & $\ldots$ \\
\hline & $p_{2-1 n}$ & 0 & 0 & 0 & 0 & 1 & 0 & $\ldots$ & 0 & 0 & 0 & 0 & $\ldots$ & 0 & 0 & 0 & 0 & $\ldots$ & 0 & 0 & 0 & 0 & $\cdots$ \\
\hline & $\vdots$ & $\vdots$ & $\vdots$ & $\vdots$ & $\vdots$ & $\vdots$ & $\because$ & $\ddots$ & $\vdots$ & $\vdots$ & $\vdots$ & $\vdots$ & $\because$ & $\vdots$ & $\vdots$ & $\vdots$ & $\vdots$ & $\because$ & $\vdots$ & $\vdots$ & $\vdots$ & $\vdots$ & $\because$ \\
\hline
\end{tabular}

TABLE II

AVERAge Magnetic TORQue CONSTITUTION IN INNER AIRGAP

\begin{tabular}{l|c}
\hline \hline \multicolumn{1}{c|}{ Pole-pair number } & \multicolumn{1}{|c}{ Magnetic torque contributed } \\
\hline$p_{1}=p_{2-11}$ & $\frac{L_{e f} R_{i n}^{2}}{\mu_{0}}\left[\pi\left(a_{0} f_{-11}-b_{0} e_{-11}\right) \sin \left(p_{2} \theta_{20}-p_{1} \theta_{10}\right)\right]$ \\
\hline$p_{2}=p_{1-11}$ & $\frac{L_{e f} R_{i n}^{2}}{\mu_{0}}\left[\pi\left(f_{0} a_{-11}-e_{0} b_{-11}\right) \sin \left(p_{2} \theta_{20}-p_{1} \theta_{10}\right)\right]$ \\
\hline$p_{2-1(k+1)}=p_{11 k}$ & $\frac{L_{e f} R_{i t}^{2}}{\mu_{0}}\left[\pi\left(a_{1 k} f_{-1(k+1)}-b_{1 k} e_{-1(k+1)}\right) \sin \left(p_{2} \theta_{20}-p_{1} \theta_{10}\right)\right]$ \\
$(k=1,2, \ldots)$ & $\frac{L_{e f} R_{t i n}^{2}}{\mu_{0}}\left[\pi\left(f_{1 k} a_{-1(k+1)}-e_{1 k} b_{-1(k+1)}\right) \sin \left(p_{2} \theta_{20}-p_{1} \theta_{10}\right)\right]$ \\
\hline$p_{1-1(k+1)}=p_{21 k}$ & $(k=1,2, \ldots)$
\end{tabular}

TABLE III

AVERAge Magnetic ToRQue CONSTITUTION IN OUTER AIRGAP

\begin{tabular}{l|c}
\hline \hline Pole-pair number & \multicolumn{1}{|c}{ Magnetic torque contributed } \\
\hline$p_{1}=p_{2-11}$ & $\frac{L_{e f} R_{\text {out }}^{2}}{\mu_{0}}\left[\pi\left(c_{0} h_{-11}-d_{0} g_{-11}\right) \sin \left(p_{2} \theta_{20}-p_{1} \theta_{10}\right)\right]$ \\
\hline$p_{2}=p_{1-11}$ & $\frac{L_{e f} R_{o u t}^{2}}{\mu_{0}}\left[\pi\left(h_{0} c_{-11}-g_{0} d_{-11}\right) \sin \left(p_{2} \theta_{20}-p_{1} \theta_{10}\right)\right]$ \\
\hline$p_{2-1(k+1)}=p_{11 k}$ & $\frac{L_{e f} R_{\text {out }}^{2}\left[\pi\left(c_{1 k} h_{-1(k+1)}-d_{1 k} g_{-1(k+1)}\right) \sin \left(p_{2} \theta_{20}-p_{1} \theta_{10}\right)\right]}{\mu_{0}}(k=1,2, \ldots)$ \\
\hline$p_{1-1(k+1)}=p_{21 k}$ & $\frac{L_{e f} R_{\text {out }}^{2}\left[\pi\left(h_{1 k} c_{-1(k+1)}-g_{1 k} d_{-1(k+1)}\right) \sin \left(p_{2} \theta_{20}-p_{1} \theta_{10}\right)\right]}{\mu_{0}}$ \\
$(k=1,2, \ldots)$ &
\end{tabular}

$$
\begin{aligned}
B_{\theta 1 \_ \text {in }}^{\prime}= & b_{0}^{\prime} \sin \left(p_{1}\left(\theta-\omega_{1} t\right)+p_{1} \theta_{10}\right) \\
& +\sum_{j= \pm 1} \sum_{m=1,3,5, \ldots} \sum_{k=1}^{\infty} b_{j k m} \\
& \times \sin \left[p_{1 j k m}\left(\theta-\omega_{1 j k m} t\right)+j m p_{1} \theta_{10}\right] .
\end{aligned}
$$

The harmonic pole-pair number is given by

$$
\begin{aligned}
p_{1 j k m} & =k N_{s}+j m p_{1} \\
j & =1,-1, \quad k=1,2, \ldots, \infty, \quad m=1,3,5, \ldots, \infty .
\end{aligned}
$$

The corresponding rotational speed is given by

$$
\omega_{1 j k m}=\frac{j m p_{1} \omega_{1}}{k N_{s}+j m p_{1}}
$$

Similar to (29) and (30), the radial and tangential flux densities can be expressed in terms of the following harmonic components:

$b_{r_{-} \text {in }}^{\prime}=a_{1 k_{1} m_{1}} \cos \left(p_{11 k_{1} m_{1}}\left(\theta-\omega_{11 k_{1} m_{1}} t\right)+m_{1} p_{1} \theta_{10}\right)$

$b_{\theta \_ \text {in }}^{\prime}=b_{-1 k_{2} m_{2}} \sin \left(p_{1-1 k_{2} m_{2}}\left(\theta-\omega_{1-1 k_{2} m_{2}} t\right)-m_{2} p_{1} \theta_{10}\right)$.

Assuming that they have the same pole-pair number, namely, $p_{11 k_{1} m_{1}}=p_{1-1 k_{2} m_{2}}$, from (37), it yields

$$
\left(k_{1}-k_{2}\right) N_{s}=\left(m_{1}+m_{2}\right) p_{1} .
$$

Denoting $U$ as the least common multiple of $N_{s}$ and $2 p_{1}$, it is easy to find $k_{1}, k_{2}, m_{1}$, and $m_{2}$, which can satisfy

$$
\left(k_{1}-k_{2}\right) N_{s}=\left(m_{1}+m_{2}\right) p_{1}=n U
$$


where $n$ can be chosen as any natural number. By using (31) and (39)-(42), it yields

$$
\begin{aligned}
\int_{0}^{2 \pi} & b_{r_{\text {_in }}}^{\prime} b^{\prime}{ }_{\text {-in }} d \theta \\
& =a_{1 k_{1} m_{1}} b_{-1 k_{2} m_{2}} \pi \sin \left(\left(m_{1}+m_{2}\right) p_{1}\left(\omega_{1} t-\theta_{10}\right)\right) \\
& =a_{1 k_{1} m_{1}} b_{-1 k_{2} m_{2}} \pi \sin \left(n U\left(\omega_{1} t-\theta_{10}\right)\right) .
\end{aligned}
$$

Hence, the developed magnetic torque on the inner rotor has a component fluctuating with time $t$, so-called the torque ripple, and can be expressed as

$$
T_{\text {ripple_in }}=\sum_{n=1}^{\infty} s_{n \_ \text {in }} \sin \left(n U\left(\omega_{1} t-\theta_{10}\right)\right)
$$

where $s_{n \_ \text {in }}$ is the Fourier coefficient.

Similarly, the pole-pair number of the harmonics excited by the outer rotor is given by

$$
\begin{aligned}
p_{2 j k m} & =k N_{s}+j m p_{2} \\
j & =1,-1, \quad k=1,2, \ldots, \infty, \quad m=1,3,5, \ldots, \infty .
\end{aligned}
$$

The corresponding rotational speed is given by

$$
\omega_{2 j k m}=\frac{j m p_{2} \omega_{2}}{k N_{s}+j m p_{2}} .
$$

Consequently, the torque ripple on the outer rotor can be obtained as

$$
T_{\text {ripple_out }}=\sum_{n=1}^{\infty} s_{n \_ \text {out }} \sin \left(n W\left(\omega_{2} t-\theta_{20}\right)\right)
$$

where $W$ is the least common multiple of $N_{s}$ and $2 p_{2}$, and $s_{n_{-} \text {out }}$ is the Fourier coefficient.

With no doubt, the existence of torque ripples will be detrimental to the performance of all machines [22], [23], including the magnetic gear. The adoption of Halbach PM arrays can significantly improve the flux distribution, thus help to eliminate or greatly reduce such torque ripples. This improvement is very essential for coaxial magnetic gears, especially for application to servomechanism.

\section{Performance Analysis}

By using time-stepping FEM, the performances of the proposed magnetic gear and the conventional coaxial magnetic gear are quantitatively compared. Table IV lists the major parameters of both gears, which hold exactly the same size. With the number of pole pairs on the inner rotor and the outer rotor equal to 4 and 17 , respectively, the gear ratio $G_{\mathrm{r}}=4.25$ is resulted.

\section{A. Magnetic Field Distribution and Harmonics Analysis}

Fig. 7 shows the magnetic field distributions of both magnetic gears. It can be easily observed that the proposed magnetic gear exhibits much lower magnetic flux density in both the inner rotor yoke and the outer rotor yoke than that in the conventional
TABLE IV

PARAMETERS OF MAGNETIC GEAR

\begin{tabular}{ll}
\hline \hline No. of pole-pairs on inner rotor & 4 \\
No. of pole-pairs on outer rotor & 17 \\
No. of ferromagnetic segments on stationary ring & 21 \\
Inside radius of inner rotor yoke [mm] & 40 \\
Outside radius of inner rotor yoke [mm] & 60 \\
Thickness of PMs on inner rotor [mm] & 10 \\
Length of inner airgap [mm] & 0.6 \\
Thickness of stationary ring [mm] & 15 \\
Length of outer airgap [mm] & 0.6 \\
Thickness of PMs on outer rotor [mm] & 10 \\
Inside radius of outer rotor yoke [mm] & 96.2 \\
Outside radius of outer rotor yoke [mm] & 106.2 \\
Axial length [mm] & 40 \\
Remanence of the PMs [T] & 1.05 \\
\hline \hline
\end{tabular}

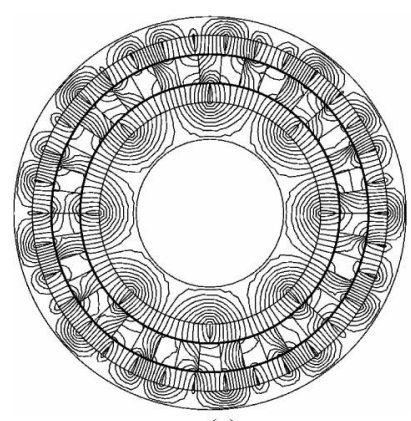

(a)

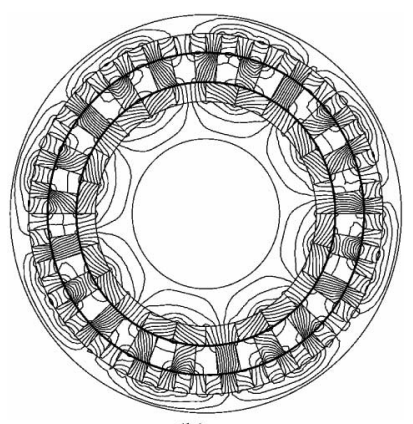

(b)
Fig. 7. Magnetic field distributions. (a) Conventional. (b) Proposed.

magnetic gear. As a result, the rotor yokes can be further diminished, hence reducing the overall weight and volume of the gear, as well as the inertias of the rotors.

Figs. 8 and 9 show the radial and tangential magnetic flux density waveforms in the inner airgap of both magnetic gears, respectively. Fig. 10 shows their harmonic spectra. From the theoretical analysis summarized in Table II, the harmonic components with the pole-pair numbers equal to $p_{1}=4, p_{2}=17$, $p_{111}=25, p_{112}=46$, and $p_{211}=38$ are effective harmonics that can contribute to torque transmission in the inner airgap. It can be seen that these effective harmonics match with the major harmonics in the harmonic spectrum shown in Fig. 10. Moreover, the harmonic components with $12,20,28,33,36,41$, and 49 pole pairs that exist in the conventional magnetic gear are significantly suppressed in the proposed magnetic gear. From (37), the harmonics with $p_{1113}=33, p_{1115}=41$, and $p_{1117}=49$ are the source of torque ripples. From (45) and (46), the harmonics with $p_{2-133}=12, p_{2-155}=20, p_{2-177}=28$, and $p_{2-199}=36$ rotate at the same speed with $\omega_{1}$, which arouse iron losses in the stationary ring.

Figs. 11 and 12 show the radial and tangential magnetic flux density waveforms in the outer airgap of both magnetic gears, respectively. Fig. 13 shows their harmonic spectra. From Table III, the harmonics with $p_{1}=4, p_{2}=17, p_{111}=$ $25, p_{112}=46, p_{113}=67, p_{114}=88, p_{114}=109, p_{211}=38$, $p_{212}=59, p_{213}=80$, and $p_{213}=101$ are effective harmonics 

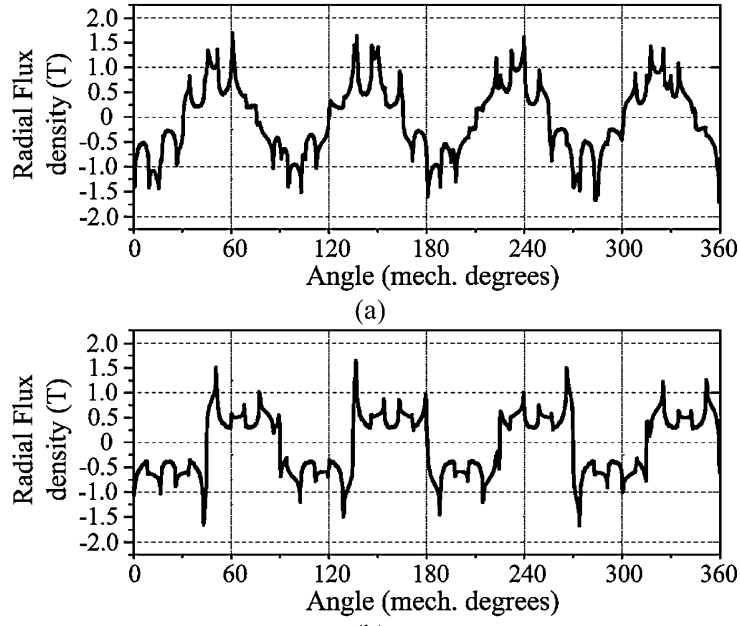

(b)

Fig. 8. Radial flux densities in inner airgap. (a) Proposed. (b) Conventional.

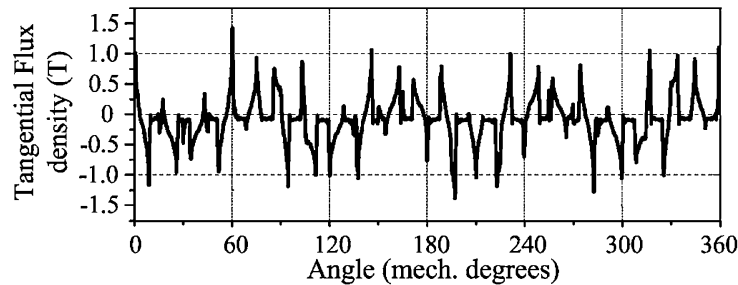

(a)

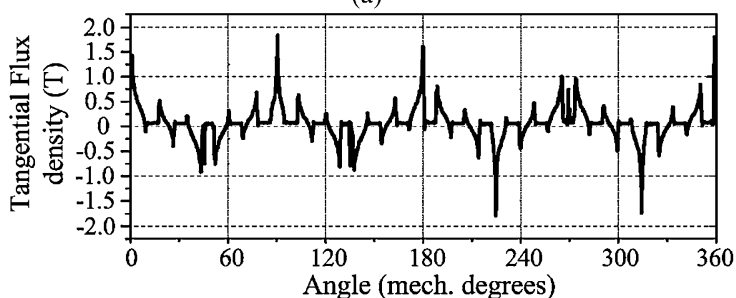

(b)

Fig. 9. Tangential flux densities in inner airgap. (a) Proposed. (b) Conventional.

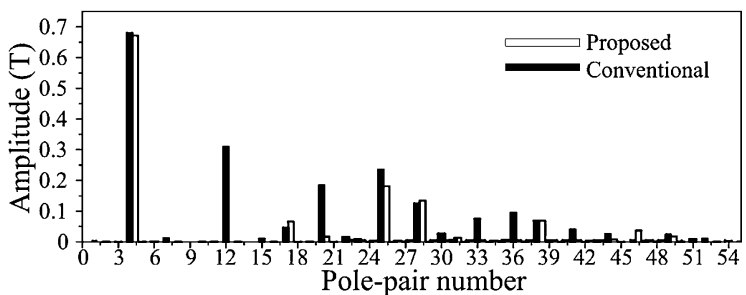

(a)

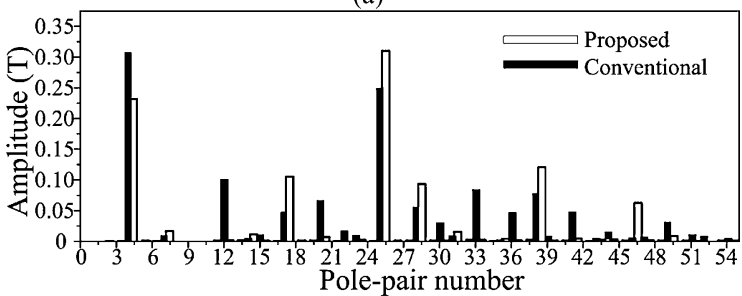

(b)

Fig. 10. Harmonic spectra of flux densities in inner airgap. (a) Radial. (b) Tangential.

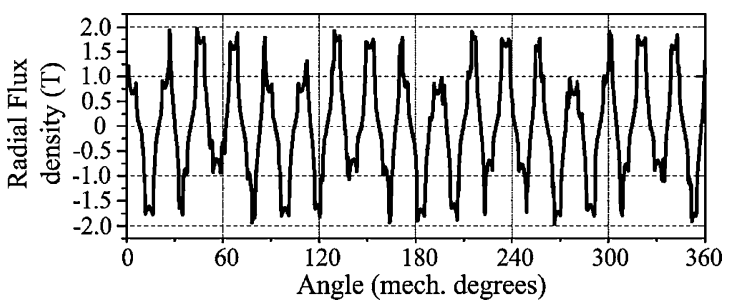

(a)

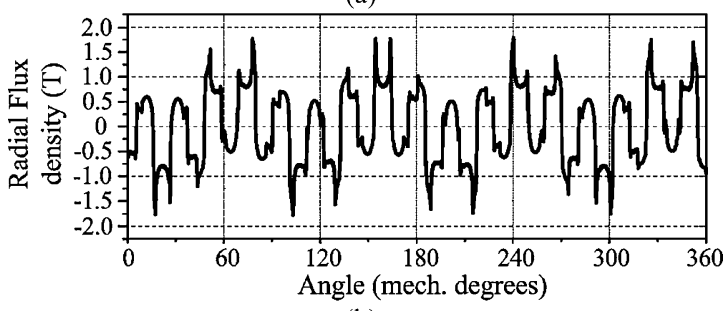

(b)

Fig. 11. Radial flux densities in outer airgap. (a) Proposed. (b) Conventional.

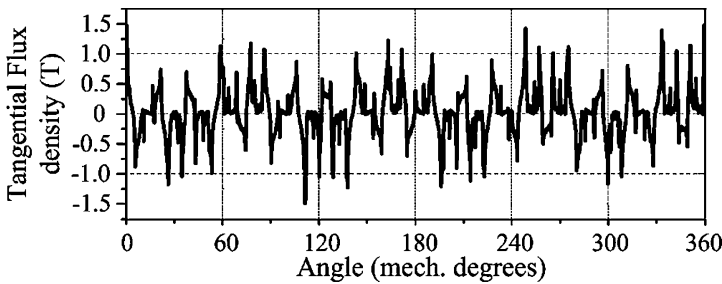

(a)

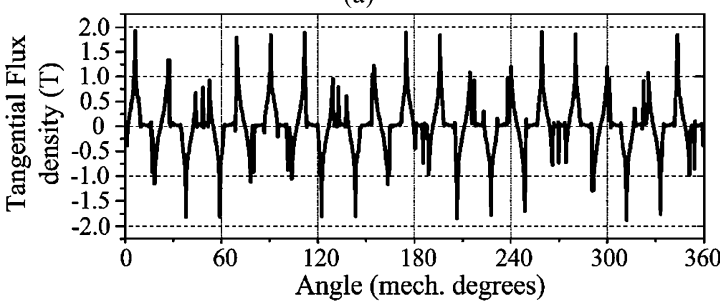

(b)

Fig. 12. Tangential flux densities in outer airgap. (a) Proposed. (b) Conventional.

that can contribute to torque transmission in the outer airgap. As expected, they match with those major harmonics shown in Fig. 13. Moreover, the harmonic components with 51, 72, 85, 106 , and 109 pole pairs that exist in the conventional magnetic gear are significantly suppressed in the proposed magnetic gear. From (45), the harmonics with $p_{2113}=72$ and $p_{2115}=106$ are the source of torque ripples. From (37) and (38), the harmonics with $p_{1-133}=51, p_{1-155}=85$, and $p_{1-177}=109$ rotate at the same speed with $\omega_{2}$, which arouse iron losses in the stationary ring.

\section{B. Torque-Angle Curve and Torque Ripples}

By holding the outer rotor still and incrementally rotating the inner rotor, the magnetic torques can be calculated by using the time-stepping FEM. These torque-angle curves are shown in Fig. 14. It can be found that the torques vary sinusoidally with the angles, which well agree with the results listed in Tables II 


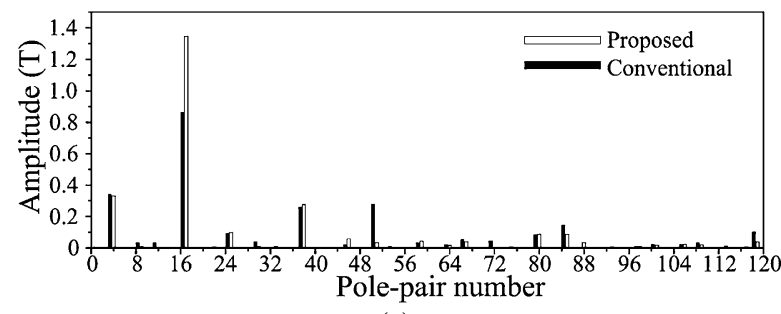

(a)

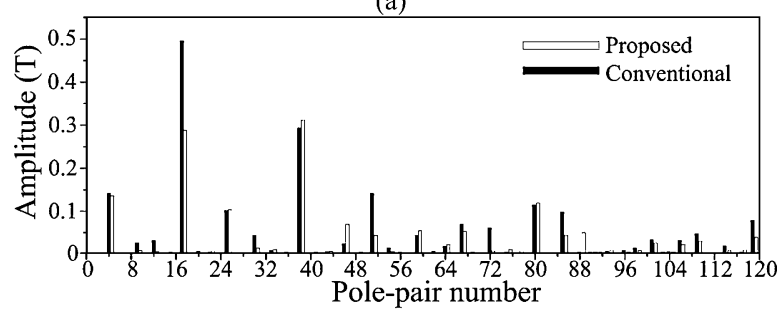

(b)

Fig. 13. Harmonic spectra of flux densities in outer airgap. (a) Radial. (b) Tangential.

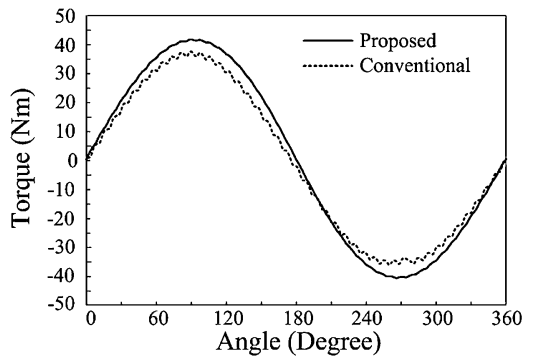

(a)

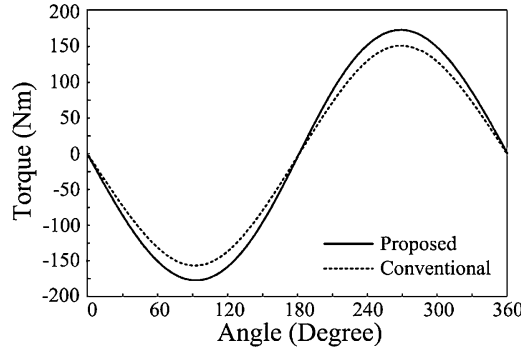

(b)

Fig. 14. Torque-angle curves. (a) Inner rotor. (b) Outer rotor.

and III. Moreover, there is a $\pi$ difference between the phase angles of inner rotor and outer rotor curves. This implies that the two rotors rotate in opposite directions, which agrees with (27).

The maximum values of the torque-angle curves denote the pull-out torques. On the inner rotor, the pull-out torque of the proposed magnetic gear is $41.4 \mathrm{~N} \cdot \mathrm{m}$, which is $13 \%$ higher than that of the conventional one $(36.6 \mathrm{~N} \cdot \mathrm{m})$. On the outer rotor, the pull-out torque of the proposed magnetic gear is $175.7 \mathrm{~N} \cdot \mathrm{m}$, which is also $13 \%$ higher than that of the conventional one $(155.3 \mathrm{~N} \cdot \mathrm{m})$. Hence, the proposed magnetic gear can offer $13 \%$ higher torque density. It should be noted that the unique feature of much lower flux density in both rotor yokes, and hence, the reduction of iron material has not been taken into account for the above assessment of torque densities. Thus, if taking into account the reduction of the iron material, the proposed magnetic gear will have further improvement.

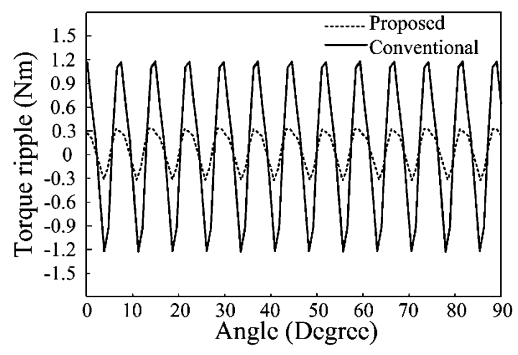

Fig. 15. Torque ripples on inner rotor.

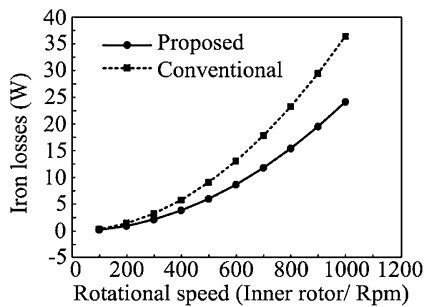

(a)

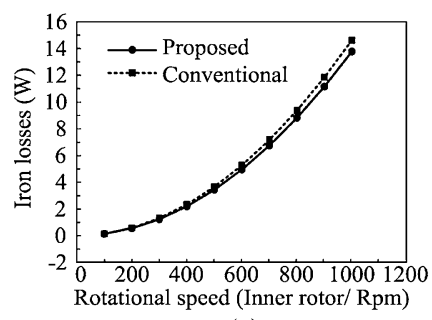

(c)

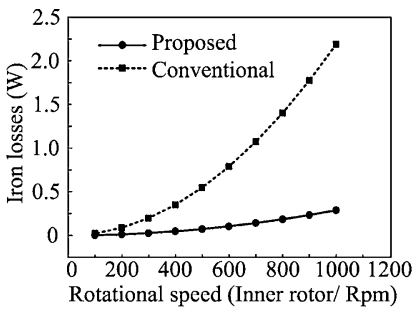

(b)

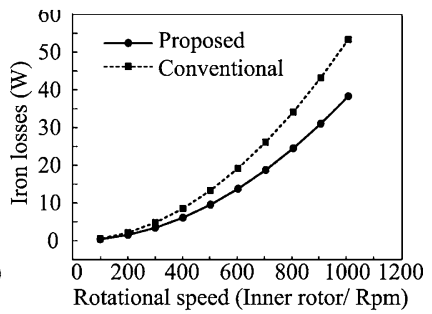

(d)
Fig. 16. Iron losses at different rotational speeds. (a) Stationary ring. (b) Inner rotor yoke. (c) Outer rotor yoke. (d) Total iron yoke.

Fig. 15 shows the torque ripples on the inner rotors of the two magnetic gears. It can be seen that the cogging torque in the proposed magnetic gear is only about $0.3 \mathrm{~N} \cdot \mathrm{m}$, which is much less than $1.2 \mathrm{~N} \cdot \mathrm{m}$ in the conventional magnetic gear, leading to $67 \%$ reduction in cogging torque.

\section{Iron Losses}

The transmission loss of magnetic gears consists of the iron losses, friction loss, windage loss, and stray loss, in which the iron losses are considered as the major contributor.

By using the time-stepping FEM, the iron losses can be estimated [24], [25]. Fig. 16 shows the no-load iron losses at various speeds in the stationary ring, the inner rotor yoke, the outer rotor yoke, and the whole magnetic gear. It can be observed that the iron losses in any components of the proposed magnetic gear are typically lower than that of the conventional one. When the inner rotor rotates at $1000 \mathrm{r} / \mathrm{min}$, the total iron losses in the proposed magnetic gear and its conventional counterpart are 38.3 and $53.3 \mathrm{~W}$, respectively. It verifies that the use of the Halbach PM arrays for the coaxial magnetic gear can typically result in $28 \%$ reduction of the total iron losses. 


\section{CONCLUSION}

In this paper, a coaxial magnetic gear with Halbach PM arrays has been proposed. The configuration and theoretical analysis of the proposed magnetic gear has been discussed. By using the time-stepping FEM, the performance analysis quantitatively verifies that the proposed magnetic gear can offer at least $13 \%$ higher torque density, up to $67 \%$ lower cogging torque, and typically $28 \%$ lower iron losses than the conventional one.

\section{REFERENCES}

[1] H. Polinder, F. F. A. van der Pijl, G.-J. de Vilder, and P. J. Tavner, "Comparison of direct-drive and geared generator concepts for wind turbines," IEEE Trans. Energy Convers., vol. 21, no. 3, pp. 725-733, Sep. 2006.

[2] K. T. Chau and C. C. Chan, "Emerging energy-efficient technologies for hybrid electric vehicles," Proc. IEEE, vol. 95, no. 4, pp. 821-835, Apr. 2007.

[3] E. P. Furlani, "A two-dimensional analysis for the coupling of magnetic gears," IEEE Trans. Magn., vol. 33, no. 3, pp. 2317-2321, May 1997.

[4] K. Atallah and D. Howe, "A novel high-performance magnetic gear," IEEE Trans. Magn., vol. 37, no. 4, pp. 2844-2846, Jul. 2001.

[5] K. Atallah, S. D. Calverley, and D. Howe, "High-performance magnetic gears," J. Magn. Magn. Mater, vol. 272-276, sup. 1, pp. E1727-1729, May 2004

[6] K. Atallah, S. D. Calverley, and D. Howe, "Design, analysis and realisation of a high-performance magnetic gear," Inst. Electr. Eng. Proc. Electr. Power Appl., vol. 151, no. 2, pp. 135-143, Mar. 2004.

[7] P. O. Rasmussen, T. O. Andersen, F. T. Jorgensen, and O. Nielsen, "Development of a high-performance magnetic gear," IEEE Trans. Ind. Appl., vol. 41, no. 3, pp. 764-770, May/Jun. 2005

[8] S. Mezani, K. Atallah, and D. Howe, "A high-performance axial-field magnetic gear," J. Appl. Phys., vol. 99, pp. 08R303-1-08R303-3, 2006.

[9] K. Atallah, J. Wang, and D. Howe, "A high-performance linear magnetic gear," J. Appl. Phys., vol. 97, pp. 10N516-1-10N516-3, 2006.

[10] K. Atallah, J. Wang, S. Mezani, and D. Howe, "A novel high-performance linear magnetic Gear," Inst. Electr. Eng. J. Ind. Appl., vol. 126, no. 10, pp. 1352-1356, 2006.

[11] K. T. Chau, D. Zhang, J. Z. Jiang, C. Liu, and Y. J. Zhang, "Design of a magnetic-geared outer-rotor permanent-magnet brushless motor for electric vehicles," IEEE Trans. Magn., vol. 43, no. 6, pp. 2504-2506, Jun. 2007.

[12] H.-S. Yan and Y.-C. Wu, "A novel design of a brushless dc motor integrated with an embedded planetary gear train," IEEE/ASME Trans. Mechatronics, vol. 11, no. 5, pp. 551-557, Oct. 2006.

[13] D. L. Trumper, M. E. Williams, and M. E. Nguyen, "Magnet arrays for synchronous machines," in Proc. IEEE Ind. Appl. Soc. Annu. Meeting, Oct. 1993, vol. 1, pp. 9-18.

[14] Z. Q. Zhu and D. Howe, "Halbach permanent magnet machines and applications: a review," Inst. Electr. Eng. Proc. Electr. Power Appl., vol. 148, no. 4, pp. 299-308, Jul. 2001.

[15] D. L. Trumper, W. Kim, and M. E. Williams, "Design and analysis framework for linear permanent-magnet machines," IEEE Trans. Ind. Appl., vol. 32, no. 2, pp. 371-379, Mar./Apr. 1996.

[16] B. C. Mecrow, A. G. Jack, D. J. Atkinson, S. R. Green, G. J. Atkinson, A. King, and B. Green, "Design and testing of a four-phase fault-tolerant permanent-magnet machine for an engine fuel pump," IEEE Trans. Energy Convers., vol. 19, no. 4, pp. 671-678, Dec. 2004.

[17] Z. Q. Zhu, Z. P. Xia, K. Atallah, G. W. Jewell, and D. Howe, "Powder alignment system for anisotropic bonded NdFeB Halbach cylinders," IEEE Trans. Magn., vol. 36, no. 5, pp. 3349-3352, Sep. 2000.

[18] A. B. Proca, A. Keyhani, A. EL-Antably, W. Lu, and M. Dai, "Analytical model for permanent magnet motors with surface mounted magnets," IEEE Trans. Energy Convers., vol. 18, no. 3, pp. 386-391, Dec. 2003.
[19] Z. P. Xia, Z. Q. Zhu, and D. Howe, "Analytical magnetic field analysis of Halbach magnetized permanent-magnet machines," IEEE Trans. Magn., vol. 40, no. 4, pp. 1864-1872, Jul. 2004.

[20] X. Wang, Q. Li, S. Wang, and Q. Li, "Analytical calculation of air-gap magnetic field distribution and instantaneous characteristics of brushless DC motors," IEEE Trans. Energy Convers., vol. 18, no. 3, pp. 424-432, Sep. 2003.

[21] D. Zarko, D. Ban, and T. A. Lipo, "Analytical calculation of magnetic field distribution in the slotted air gap of a surface permanent-magnet motor using complex relative air-gap permeance," IEEE Trans. Magn., vol. 42, no. 7, pp. 1828-1837, Jul. 2006.

[22] D. Min, A. Keyhani, and T. Sebastian, "Torque ripple analysis of a PM brushless DC motor using finite element method," IEEE Trans. Energy Convers., vol. 19, no. 1, pp. 40-45, Mar. 2004.

[23] K. T. Chau, Q. Sun, Y. Fan, and M. Cheng, "Torque ripple minimization of doubly salient permanent magnet motors," IEEE Trans. Energy Convers., vol. 20, no. 2, pp. 352-358, Jun. 2005.

[24] C. C. Mi, G. R. Slemon, and R. Bonert, "Modeling of iron losses of permanent magnet synchronous motors," IEEE Trans. Ind. Appl., vol. 39, no. 3, pp. 734-742, May 2003

[25] C. C. Mi, G. R. Slemon, and R. Bonert, "Minimization of iron losses of permanent magnet synchronous machines," IEEE Trans. Energy Convers., vol. 20, no. 1, pp. 121-127, Mar. 2005.

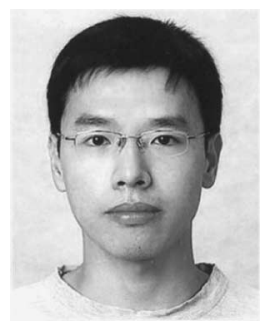

Linni Jian (S'07) received the B.Eng. degree from Huazhong University of Science and Technology, Wuhan, China, in 2003, and the M.Eng. degree from the Institute of Electrical Engineering, Chinese Academy of Science, Taipei, China, in 2006. He is currently working toward the Ph.D. degree in electrical and electronic engineering from The University of Hong Kong, Pokfulam, Hong Kong.

His current research interests include electric drives, electric vehicles, and power electronics, and the design of magnetic gears and integrated permanent-magnet machines, as well as high-efficiency machine control strategies.

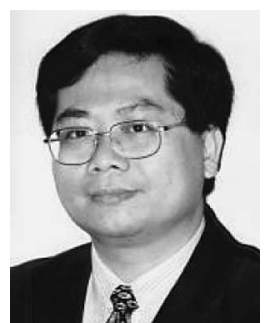

K. T. Chau (M'89-SM'04) received the B.Sc. (Eng.) (first-class honors), M.Phil., and Ph.D. degrees in electrical and electronic engineering from The University of Hong Kong, Pokfulam, Hong Kong, in 1988, 1991, and 1993, respectively.

$\mathrm{He}$ is currently a Professor in the Department of Electrical and Electronic Engineering, The University of Hong Kong, where he is also the Director of the International Research Center for Electric Vehicles. His research interests include three main areas: electric vehicles, electric drives, and power electronics. In these areas, he has authored or coauthored more than 200 refereed technical papers. He is also the coauthor of a monograph Modern Electric Vehicle Technology (London, U.K.: Oxford Univ. Press, 2001).

Prof. Chau is a Fellow of the Institution of Engineering and Technology (IET). He was the recipient of the Outstanding Young Researcher Award in 2003, the University Teaching Fellowship Award in 2004, and the Award for Innovative Excellence in Teaching, Learning and Technology in 2005. 